\title{
DESAIN PEMBELAJARAN UNTUK MEMBIMBING SISWA SEKOLAH DASAR DALAM MEMPEROLEH LITERASI SAINTIFIK
}

\section{LEARNING DESIGN TO GUIDE PRIMARY STUDENTS ON ACHIEVING SCIENTIFIC LITERACY}

\author{
Adib Rifqi Setiawan \\ MI NU Tasywiquth Thullab Salafiyyah (TBS) Kudus, Indonesia \\ adibrifqisetiawan@gmail.com \\ $+62-856-4067-6017$
}

\begin{abstract}
Abstrak
Riset ini menyusun desain pembelajaran untuk membimbing siswa sekolah dasar dalam memperoleh literasi saintifik. Pendekatan yang digunakan ialah metode kombinasi model sequential exploratory. Hasil menunjukkan bahwa desain keabsahan dan keandalan desain ini secara umum dalam kategori dapat digunakan. Pelaksanaan kepada 35 siswa di Kabupaten Kudus menunjukkan bahwa desain ini dapat diterapkan guru serta bisa ditanggapi siswa selama pembelajaran.

Kata-kata Kunci: Desain Pembelajaran; Literasi Saintifik; Sekolah Dasar;
\end{abstract}

\begin{abstract}
This research constructs learning design to guide primary students on achieving scientific literacy. The approach used is mixed method sequential exploratory model. This results shows that validity and reliability of this design in general on the category can be used. The implementation of 35 students in Kabupaten Kudus revealed that this design could be applied by the teacher and could be responded to by students during learning.
\end{abstract}

Keywords: Learning Design; Primary School; Scientific Literacy;

\section{Pendahuluan}

Penilaian PISA (Programme for International Students Assessment) pada 2006-2019 dan beberapa kajian pada periode itu telah menemukan bahwa pembelajaran di Indonesia secara umum tidak dapat membimbing pelajar secara optimal untuk mencapai literasi saintifik (OECD, 2019; Setiawan, 2019; 2017; Utari, Karim, Prima, Saepuzaman, \& Nugaha, 2017; OECD\&ADB, 2015; Naturasari, Roshayanti, \& Nurwahyunani, 2016; Adisendjaja, 2008). Semua informasi menyampaikan simpulan bahwa pelajar Indonesia secara keseluruhan tampak tidak mengapresiasi pengetahuan ilmiah, kurang melihat peluang untuk menjadi ilmuwan, serta jarang memanfaatkan penguasaan teknis sains secara praktis di luar penyelidikan ilmiah. Mungkin hanya sebagian kecil pelajar Indonesia yang berharap untuk mengejar karier di bidang sains dibanding semua pelajar di negara berkembang ini. Di antara sebagian kecil itu, tidak terdapat jumlah yang secara signifikan memiliki kinerja tinggi dalam literasi saintifik dibanding pelajar dari negara lain yang ikut serta dalam penilaian PISA.

Sebenarnya sudah terdapat beberapa upaya untuk melatih literasi saintifik melalui pembelajaran yang dilakukan oleh pendidik maupun peneliti Indonesia. Misalnya dilakukan oleh Utari, Karim, Prima, Saepuzaman, \& Nugraha (2017) melalui pembelajaran fisika topik termodinamika di sekolah menengah. Diperoleh hasil berupa sebagian besar pelajar dapat membuat pertanyaan serta menyusun langkah eksperimen dan tabel pengamatan, tapi tidak terdapat pelajar yang mengkritik atau memberikan saran terhadap hasil percobaan yang mereka lakukan (Utari, Karim, Prima, Saepuzaman, \& Nugaha, 2017). Setiawan $(2019 ; 2017)$ melakukan upaya yang sama melalui pembelajaran fisika topik mekanika di sekolah menengah yang diukur berdasarkan instrumen susunan Setiawan, Utari, \& Nugraha (2017). Hasil menunjukkan bahwa secara keseluruhan literasi saintifik pelajar mengalami peningkatan pada kategori sedang setelah diterapkan pendekatan saintifik (Setiawan, 2019; 2017). 
Upaya serupa juga dilakukan oleh Dinata, Adisendjaja, \& Amprasto (2018) ketika melakukan field trip dalam pembelajaran biologi topik ekosistem di sekolah menengah. Diperoleh hasil berupa peningkatan kategori tinggi dalam kompetensi menjelaskan fenomena secara ilmiah serta sedang dalam menafsirkan data dan bukti secara ilmiah (Dinata, Adisendjaja, \& Amprasto, 2018). Upaya lain juga dilakukan Setiawan $(2019 ; 2019)$ melalui pembelajaran biologi topik plantae dan animalia di sekolah menengah yang diukur berdasarkan instrumen susunan Setiawan \& Mufassaroh (2019). Hasil menunjukkan bahwa perbandingan penerapan pendekatan saintifik dengan beberapa riset lain menunjukkan tidak ditemukan perbedaan menyolok antar model pembelajaran dari sisi peningkatan maupun keefektifan (Setiawan, 2019; 2019).

Upaya untuk melihat lebih rinci profil literasi saintifik siswa sekolah menengah yang dilakukan Setiawan (2019) melalui riset korelasi menggunakan instrumen Setiawan (2019), Siayah \& Setiawan (2019), serta Velasufah \& Setiawan (2019), yang mengungkap bahwa kecerdasan naturalistik dan efikasi diri memiliki korelasi kuat dengan literasi saintifik. Lebih lanjut Setiawan (2019) menyarankan agar pembelajaran dapat memfasilitasi kecerdasan dan motivasi siswa untuk membimbing siswa dalam memperoleh literasi saintifik.

Bila dicermati, kajian pustaka yang disampaikan menampakkan bahwa upaya untuk melatih literasi saintifik melalui pembelajaran lebih banyak dilakukan di sekolah menengah. Upaya yang sama belum dilakukan di sekolah dasar. Kami menganggap bahwa untuk membimbing siswa dalam memperoleh literasi saintifik, perlu sedini mungkin dimulai di sekolah dasar yang merupakan tahap awal kehidupan pelajar. Alasan utama yang mendasari anggapan kami ialah nilai penting berfokus kepada anak-anak untuk membekali keterampilan yang penting untuk keseharian, lebih efektif dalam melatih literasi saintifik di sekolah dasar yang tingkat kerumitan topik pembelajaran lebih sederhana dibanding sekolah menengah, serta lebih efisien untuk membiasakan hal ini sejak dini daripada melakukan tindakan perbaikan untuk orang yang berusia tua (Setiawan, Puspaningrum, \& Umam, 2019; Setiawan, 2020).

Berdasarkan sebaran informasi yang disampaikan, kami merasa perlu untuk menyusun desain pembelajaran untuk membimbing siswa sekolah dasar dalam memperoleh literasi saintifik. Karena itu, pertanyaan yang menjadi fokus riset ini ialah, "Bagaimana desain pembelajaran untuk membimbing siswa sekolah dasar dalam memperoleh literasi saintifik?"

\section{Metode}

Riset ini membutuhkan data berupa kajian pustaka tentang karakteristik pembelajaran sekolah dasar, indikator literasi saintifik, serta survei dan ujicoba terhadap rancangan. Berdasarkan tujuan riset dan kebutuhan data, dapat dipakai metode kombinasi (mixed method) (Sugiyono, 2018; Creswell, 2014; Fraenkel, Wallen, \& Hyun, 2012). Pendekatan ini dipilih karena kami ingin membuat desain berdasarkan kajian pustaka terkait karakteristik pembelajaran sekolah dasar dan indikator literasi saintifik. Desain tersebut kemudian dilihat keabsahan dan keandalannya berdasarkan survei kemudian diterapkan sebagai ujicoba ke dalam pembelajaran. Karena urutan awal menggunakan metode kualitatif dan akhir memakai metode kuantitatif, model kombinasi yang digunakan berupa sequential exploratory (Sugiyono, 2018; Creswell, 2014; Fraenkel, Wallen, \& Hyun, 2012).

\section{Hasil dan Pembahasan}

Peraturan Menteri Pendidikan dan Kebudayaan Republik Indonesia Nomor 24 Tahun 2016 menyampaikan bahwa pembelajaran di sekolah dasar dilaksanakan menggunakan model tematik (Kemdikbud, 2016). Model tematik adalah metode pembelajaran yang menekankan pemberian tema khusus pilihan untuk mengajarkan beberapa konsep berdasarkan paduan penggunaan ragam informasi ketika mempelajari topik tertentu (Resor, 2017; Seefeldt, 2005). 
Uraian perubahan kurikulum dari Setiawan \& Sari (2019) menunjukkan bahwa konsep paduan penggunaan ragam informasi untuk mengajar di sekolah Indonesia, secara umum bukan hal baru dan tidak sukses pada masa lalu. Sebagai tambahan, beberapa orang menanggap pembelajaran tematik adalah satu kesempatan sementara sebagian lain memandang bahwa ini memiliki masalah. Namun, jawaban untuk bagaimana penerapan pembelajaran tematik belum dikaji secara menyeluruh di Indonesia.

Pembelajaran tematik di kelas V dilaksanakan untuk mata pelajaran Pendidikan Pancasila dan Kewarganegaraan (PPKn), Bahasa Indonesia, Ilmu Pengetahuan Alam, Ilmu Pengetahuan Sosial, serta Seni Budaya dan Prakarya (SBdP) (Kemdikbud, 2016). Sebagai pelaku lapangan, keadaan yang kami alami selama debut memandu pembelajaran menggunakan model tematik pada 2020/2021 menunjukkan bahwa kelima mata pelajaran tersebut tidak selalu seperti itu. Perbedaan karakteristik antar konten pembelajaran membuat paduan lebih kerap hanya mencakup kompetensi dasar 2-3 mata pelajaran. Secara umum, mata pelajaran IPS dan PPKn tidak pernah dipadukan dengan IPA, tapi ketiganya dapat dipadukan dengan Bahasa Indonesia dan SBdP. Namun, untuk topik tertentu seperti lingkungan (ekosistem), kelima mata pelajaran tersebut dapat dipadukan secara utuh dan menyeluruh (Setiawan, 2020).

Uraian perkembangan peradaban manusia yang disajikan oleh Abū al-Fath Muhammad ibn 'Abd alKarīm al-Syahrostānī (2010) dalam bukunya al-Milal wa al-Nihal menunjukkan bahwa literasi saintifik sendiri bukan gagasan modern karena sudah muncul sejak 2.603 tahun lalu ketika Thalēs melibatkan dirinya dalam penyelidikan ilmiah termasuk juga rekayasa. Thalēs memperoleh kredit sebagai orang pertama yang berhasil memprediksi gerhana matahari pada 28 Mei 585 SM (Panchenko, 1994). Dirinya juga berhasil mendeskripsikan posisi Ursa Minor dan berpikir bahwa rasi bintang bisa berguna sebagai panduan untuk navigasi di laut (Boitani, 2015). Namun, nilai penting dari pekerjaan Thalēs ialah menggunakan rumahnya untuk menjadi tempat pembelajaran di Ionia (pada waktu itu Yunani, saat ini Turki), yang memelopori minat kuat dalam mengungkap hukum dasar guna menjelaskan fenomena alam (Setiawan, 2016). Thalēs juga memanfaatkan kemampuan memprediksi cuaca untuk membeli semua mesin pengepres zaitun di Milētos setelah memperkirakan cuaca dan panen yang baik pada tahun tertentu guna mendapatkan kekayaan dari panen zaitun sekaligus membuktikan kepada sesama warga Milētos bahwa penyelidikan ilmiah dapat berguna untuk keseharian termasuk finansial (Crawford \& Sen, 1996).

Tabel 1. Rincian Indikator setiap Kompetensi Literasi Saintifik

\begin{tabular}{|c|c|}
\hline Kompetensi & Indikator \\
\hline \multirow{2}{*}{$\begin{array}{l}\text { Menjelaskan masalah secara } \\
\text { ilmiah }\end{array}$} & Menerapkan pengetahuan ilmiah yang sesuai \\
\hline & Menyusun pertanyaan berdasarkan fokus masalah \\
\hline \multirow{2}{*}{ Menafsirkan data secara ilmiah } & Menyajikan data menggunakan beragam representasi yang sesuai \\
\hline & Menganalisis informasi dari setiap representasi \\
\hline \multirow{2}{*}{$\begin{array}{l}\text { Mengomunikasikan informasi } \\
\text { ilmiah }\end{array}$} & Menyimpulkan informasi berdasarkan analisis \\
\hline & Menjelaskan manfaat pengetahuan ilmiah bagi masyarakat \\
\hline \multirow{2}{*}{$\begin{array}{l}\text { Merencanakan penyelidikan } \\
\text { ilmiah }\end{array}$} & Menentukan variabel penyelidikan \\
\hline & $\begin{array}{c}\text { Mengusulkan cara mengeksplorasi secara ilmiah terhadap pertanyaan yang } \\
\text { diberikan }\end{array}$ \\
\hline \multirow{2}{*}{ Melakukan penyelidikan ilmiah } & $\begin{array}{l}\text { Mengidentifikasi, menggunakan, dan menghasilkan model dan representas } \\
\text { yang jelas }\end{array}$ \\
\hline & Mengidentifikasi asumsi, bukti, dan penalaran dalam bacaan \\
\hline \multirow{2}{*}{$\begin{array}{l}\text { Mengevaluasi penyelidikan } \\
\text { ilmiah }\end{array}$} & $\begin{array}{l}\text { Mengevaluasi cara mengeksplorasi secara ilmiah terhadap pertanyaan yang } \\
\text { diberikan }\end{array}$ \\
\hline & Mengevaluasi argumen dan bukti ilmiah dari beragam tipe sumber \\
\hline
\end{tabular}


Informasi tersebut menunjukkan bahwa pembelajaran di sekolah dasar yang menggunakan model tematik dipandang memiliki keselarasan dengan literasi saintifik, terjadi karena literasi saintifik menekankan kepada kecakapan untuk menerapkan pengalaman terlibat pembelajaran ke dalam keseharian, bukan sebatas menguasai konsep kurikuler tertentu (Setiawan, 2020). Berdasarkan kajian pustaka yang dilakukan terhadap Hurd (1998), Gormally, dkk. (2012), Fives, dkk. (2014), OECD (2019), serta Setiawan (2020), indikator literasi saintifik yang kami rancang fokus terhadap kompetensi yang secara rinci dapat dilihat melalui tabel 1.

Setelah indikator ditentukan, kami menyusun instrumen penilaian pembelajaran. Pilihan ini diambil karena dengan acuan penilaian tersebut, dapat dirancang proses pembelajaran yang perlu dialami oleh siswa. Agar tujuan proses tersebut selaras dengan hasil yang diharapkan, kami turut menyusun lembar kegiatan siswa (LKS). LKS juga berguna untuk memudahkan pelaksanaan sekaligus mengevaluasi proses pembelajaran. Berdasarkan istrumen penilaian pembelajaran tersebut, kemudian dibuat susunan acuan desain pembelajaran dalam bentuk matriks. Dengan demikian, desain pembelajaran dibuat berdasarkan hasil yang diharapkan dan proses yang memungkinkan untuk diterapkan.

Instrumen penilaian pembelajaran yang dirancang berupa tes penguasaan konsep dan tes literasi saintifik. Rancangan ini dipilih agar tujuan pembelajaran di sekolah dengan literasi saintifik dapat dipadukan. Rincian topik yang diujikan untuk tes konsep ialah: Hak dan Kewajiban (PPKn), Teks Eksplanasi (Bahasa Indonesia), Lingkungan dan Panas (IPA), Kegiatan Ekonomi (IPS), dan Seni Rupa (PJOK). Sementara literasi saintifik difokuskan kepada domain kompetensi yang rincian indikator dapat dilihat melalui tabel 1. Instrumen tersebut disusun dalam tes objektif beralasan untuk menghindari kesubjektifan dalam memeriksa jawaban, mengurangi kesulitan dalam memberikan skor, serta meminimalisir waktu pengoreksian instrumen. Selain itu, dalam keseharian, biasanya seseorang sudah memiliki beberapa pilihan dalam membuat keputusan. Keberadaan pilihan jawaban dipakai untuk membiasakan siswa untuk membuat keputusan berdasarkan beberapa pilihan. Penambahan alasan dipakai untuk mengarahkan siswa kepada jawaban yang diharapkan serta mengurangi peluang menjawab secara spekulatif. Sehingga keberadaan alasan dipakai sebagai faktor tebakan (koefisien penilaian). Dengan demikian, penilaian setiap butir soal dilakukan menggunakan persamaan 1 dengan acuan dari tabel 2:

$$
\begin{aligned}
& N_{i}=S_{i} \times F_{i} \\
& \text { keterangan: } \\
& N_{i} \quad \text { = nilai setiap butir soal (nilai 0-2) } \\
& S_{i} \quad \text { = skor setiap butir pilihan jawaban (nilai 0-1) } \\
& F_{i} \quad=\text { skor faktor tebakan setiap butir soal (nilai 0-2) }
\end{aligned}
$$

(Persamaan 1. penilaian setiap butir soal)

Tabel 2. Klasifikasi Faktor Tebakan

\begin{tabular}{cc}
\hline Skor & Bentuk Uraian \\
\hline 2 & Alasan terkait serta mendukung jawaban yang dipilih \\
\hline 1 & Alasan terkait, tapi tidak mendukung jawaban yang dipilih \\
\hline 0 & Alasan tidak terkait dengan jawaban yang dipilih \\
\hline 0 & Alasan tidak disampaikan \\
\hline
\end{tabular}

Dalam pelaksanaan proses pembelajaran, siswa diberi LKS yang memuat konsep tertentu dengan langkah sesuai indikator literasi saintifik guna menuntun siswa untuk mencapai hasil belajar sesuai indikator yang telah ditetapkan. LKS disusun berdasarkan model yang dipakai dalam setiap proses pembelajaran, meliputi: group work dan guided inquiry. Pembedaan tersebut diambil karena karakteristik topik yang dibahas dan kompetensi yang dibekalkan tidak sama sepenuhnya, sehingga gambaran kegiatan pembelajaran tidak dapat disamakan seluruhnya. Group work dipakai supaya membekali siswa untuk dapat berkolaborasi dalam membahas masalah tertentu, yang dipandang selaras 
untuk membahas topik Teks Eksplanasi (Bahasa Indonesia), Hak dan Kewajiban (PPKn), serta Kegiatan Ekonomi (IPS) (Siayah, Kurniawati, Velasufah, \& Setiawan, 2019). Model guided inquiry dipilih karena gambaran kegiatan untuk setiap tahap pembelajaran yang menekankan siswa agar dapat mengembangkan keterampilan ilmiah, yang dianggap cocok untuk membahas topik Teks Eksplanasi (Bahasa Indonesia), Lingkungan dan Panas (IPA), serta dan Seni Rupa (PJOK) (Siayah, Kurniawati, Velasufah, \& Setiawan, 2019).

Keabsahan instrumen penilaian pembelajaran dan LKS ditentukan berdasarkan validasi pakar (Fraenkel, Wallen, \& Hyun, 2012). Validasi dilakukan terhadap keselarasan instrumen penilaian pembelajaran dan LKS dengan program yang dikembangkan, kesesuaian indikator dengan soal, ketepatan jawaban dengan pertanyaan, serta kecocokan soal dengan jenjang sekolah. Pakar yang dipilih yaitu akademisi yang memiliki kepakaran literasi saintifik (1 orang), pendidikan dasar (1 orang), evaluasi pembelajaran (1 orang), dan model pembelajaran (1 orang), serta praktisi pembelajaran sekolah dasar (1 orang) dan penyunting naskah bacaan anak (1 orang). Hasil validasi berupa penilaian terhadap setiap butir soal yang diolah menggunakan persamaan 2 kemudian ditafsirkan berdasarkan tabel 3. Berdasarkan tabel tersebut, instrumen penilaian pembelajaran dan LKS dapat digunakan kalau memenuhi kriteria 'sangat layak' atau 'cukup layak'.

$$
\begin{aligned}
& P(s)=\frac{s}{N} \times 100 \% \\
& \text { keterangan: } \\
& P(s) \quad=\text { persentase setiap butir soal } \\
& s \quad=\text { skor setiap butir soal } \\
& N \quad=\text { jumlah keseluruhan butir soal }
\end{aligned}
$$$$
\text { (Persamaan 2. Pengolahan Hasil Validasi) }
$$

Tabel 3. Penafsiran Penilaian

\begin{tabular}{cc}
\hline Rentang Rerata Penilaian Pakar (\%) & Kriteria Kelayakan Instrumen \\
\hline $7,001 \leq \% \leq 10,000$ & Sangat layak \\
\hline $4,001 \leq \% \leq 7,000$ & Cukup layak \\
\hline $0,000 \leq \% \leq 4,000$ & Tidak layak \\
\hline
\end{tabular}

Untuk keandalan instrumen penilaian pembelajaran dan LKS diukur berdasarkan nilai konsistensi internal (internal consistency), yang diolah menggunakan persamaan 3 kemudian ditafsirkan berdasarkan tabel 4. Berdasarkan tabel tersebut, instrumen penilaian pembelajaran dan LKS dapat digunakan nilai $\propto$ sebagai acuan koefisien keandalan (reliability coefficient) besar dari 0,700 (Fraenkel, Wallen, \& Hyun, 2012; Cronbach, 1951).

$$
\begin{aligned}
& \alpha=\frac{n}{n-1}\left(1-\frac{\sum_{i} V_{i}}{V_{t}}\right) \quad \text { (Persamaan 3. } \\
& \text { keterangan: } \\
& \begin{array}{lcl}
\alpha \quad=\text { koefisien alfa } & n & =\text { jumlah butir soal } \\
V_{i} \quad=\text { simpangan baku setiap butir soal } & V_{t}=\text { simpangan baku keseluruhan }
\end{array}
\end{aligned}
$$

Tabel 4. Penafsiran Penilaian Keandalan Instrumen

\begin{tabular}{cc}
\hline Nilai Alfa Cronbach $(\boldsymbol{\alpha})$ & Kategori Konsistensi Internal \\
\hline$\alpha \leq 0,9$ & Luar biasa \\
\hline $0,8 \leq \alpha<0,9$ & Baik \\
\hline $0,7 \leq \alpha<0,8$ & Dapat diterima \\
\hline $0,6 \leq \alpha<0,7$ & Dipertanyakan \\
\hline $0,5 \leq \alpha<0,6$ & Rendah \\
\hline$\alpha<0,5$ & Tidak dapat diterima \\
\hline
\end{tabular}


Dalam melaksanakan ujicoba tersebut kami memilih partisipan sebanyak 17 orang yang dipilih menggunakan teknik convenience sampling karena keterbatasan tenaga (Fraenkel, Wallen, \& Hyun, 2012). Hasil validasi pakar dan ujicoba dapat dilihat melalui tabel 5. Hasil berupa instrumen penilaian dan LKS ini dapat digunakan sebagai bahan penyusunan program pembelajaran yang gambaran umum diperlihatkan melalui tabel 6.

Tabel 5. Hasil Validasi Pakar dan Ujicoba Terbatas

\begin{tabular}{ccccccccccc} 
Susunan & & \multicolumn{1}{c}{ Validasi Pakar } & & Uji Coba \\
& $\mathbf{1}$ & $\mathbf{2}$ & $\mathbf{3}$ & $\mathbf{4}$ & $\mathbf{5}$ & $\mathbf{6}$ & Rerata & Kelayakan & $\boldsymbol{\alpha}$ & Keabsahan \\
LKS Topik Hak dan & 5 & 7 & 5 & 7 & 7 & 6 & 6,167 & Cukup Layak & 0,962 & Dapat digunakan \\
Kewajiban (PPKn), & 7 & 8 & 7 & 6 & 7 & 8 & 7,167 & Cukup Layak & 0,710 & Dapat digunakan \\
Teks Eksplanasi & 7 & 8 & 7 & 6 & 7 & 7 & 7,000 & Cukup Layak & 0,983 & Dapat digunakan \\
(Bahasa Indonesia), & 8 & 7 & 7 & 7 & 7 & 7 & 7,167 & Sangat Layak & 0,724 & Dapat digunakan \\
serta Kegiatan & 7 & 8 & 5 & 5 & 7 & 6 & 6,333 & Cukup Layak & 0,932 & Dapat digunakan \\
Ekonomi (IPS) & 7 & 7 & 7 & 6 & 7 & 7 & 6,833 & Cukup Layak & 0,843 & Dapat digunakan \\
& 7 & 8 & 7 & 5 & 7 & 7 & 6,833 & Cukup Layak & 0,901 & Dapat digunakan \\
LKS Topik Teks & 8 & 7 & 5 & 6 & 7 & 7 & 6,667 & Cukup Layak & 0,839 & Dapat digunakan \\
Eksplanasi (Bahasa & 7 & 8 & 7 & 6 & 7 & 7 & 7,000 & Cukup Layak & 0,703 & Dapat digunakan \\
Indonesia), Ekosistem & 8 & 7 & 7 & 7 & 7 & 7 & 7,167 & Sangat Layak & 0,943 & Dapat digunakan \\
dan Panas (IPA), serta & 7 & 7 & 7 & 5 & 7 & 5 & 6,333 & Cukup Layak & 0,839 & Dapat digunakan \\
Seni Rupa (SBdP) & 7 & 8 & 7 & 4 & 7 & 7 & 6,667 & Cukup Layak & 0,772 & Dapat digunakan \\
& 7 & 7 & 7 & 7 & 7 & 7 & 7,000 & Cukup Layak & 0,824 & Dapat digunakan \\
Tes Konsep & 9 & 8 & 7 & 5 & 7 & 8 & 7,333 & Sangat Layak & 0,848 & Dapat digunakan
\end{tabular}

Keseluruhan hasil yang kami hasilkan dapat disebar secara luas dalam satu paket perangkat pembelajaran atau terpisah. Penyebaran ini dapat digunakan untuk keperluan praktik pembelajaran maupun replikasi riset. Satu paket yang dimaksud ialah digunakan seutuhnya berdasarkan kerja kami. Sedangkan terpisah berarti hanya diambil seperlunya, seperti instrumen penilaian pembelajaran untuk mengukur profil literasi saintifik siswa.

Keterbatasan tenaga membuat kami melaksanakan desain terbatas di satu rombel. Penerapan program pembelajaran dilakukan terbatas di satu kelas, yaitu kelas V di salah satu madrasah ibtidaiyyah di Kabupaten Kudus. Di kelas ini pembelajaran tematik dilakukan sebanyak 4 pertemuan dengan total alokasi waktu sebanyak 11 jam pembelajaran setiap pekan. Aspek yang diperhatikan dalam penerapan program ialah pelaksanaan guru dan tanggapan siswa. Pelaksanaan guru dilihat berdasarkan catatan pelaksanaan pembelajaran, sementara tanggapan siswa dilihat berdasarkan isian dalam LKS. Dapat dilihat di gambar 1 bahwa program dapat diterapkan hampir maksimal di setiap tahap. Rincian data menunjukkan bahwa rerata pelaksanaan guru sebesar 75,17 dan tanggapan siswa sebesar 69,17.

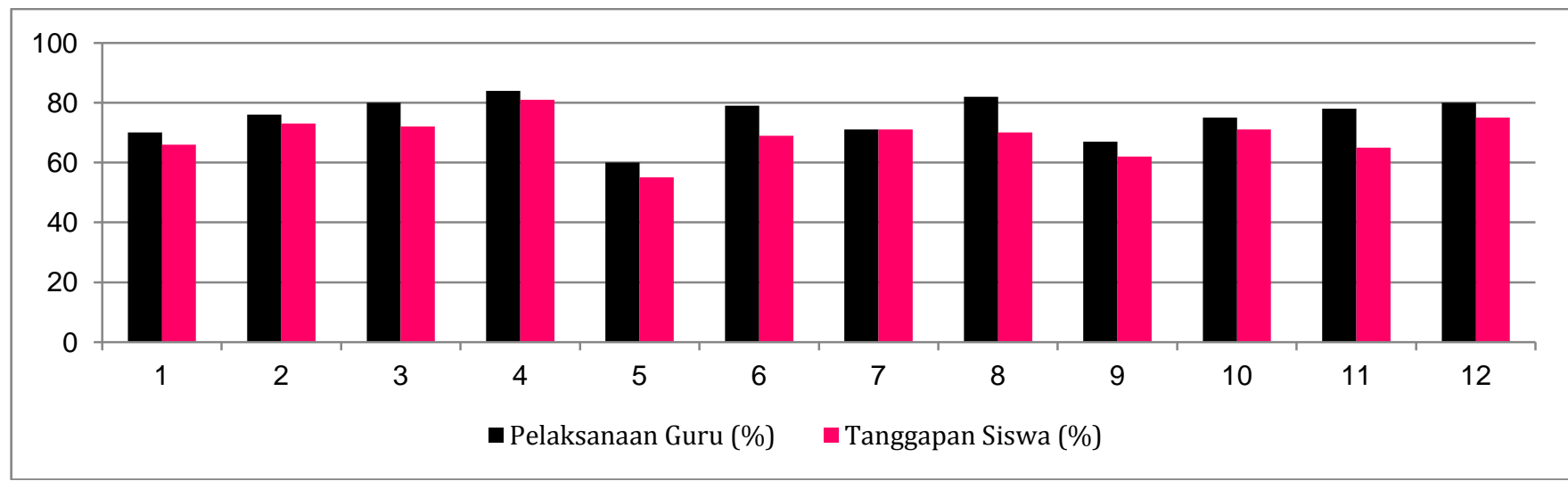

Gambar 1. Pelaksanaan Program Pembelajaran 


No
1
2
3
4
5
6

\section{No. Tahap}

Pendahuluan 2

Inti

\section{Langkah \\ Apersepsi \\ Motivasi}

Mengamati

Menanya

Mengolah informasi

Mengomunikasikan hasil

Menelaah kembali

Informasi

Tabel 6. Matriks indikator literasi saintifik dengan langkah pembelajaran

\section{Kompetensi}

Menjelaskan masalah secara ilmiah

Melakukan penyelidikan ilmiah

Merencanakan penyelidikan ilmiah

Menjelaskan masalah secara ilmiah

Merencanakan penyelidikan ilmiah

Melakukan penyelidikan ilmiah

Menafsirkan data secara ilmiah

Menafsirkan data secara ilmiah

Mengomunikasikan informasi ilmiah

Mengomunikasikan informasi ilmiah

Mengevaluasi penyelidikan ilmiah

Mengevaluasi penyelidikan ilmiah

\section{Indikator}

Menerapkan pengetahuan ilmiah yang sesuai

Mengidentifikasi, menggunakan, dan menghasilkan model dan representasi yang jelas

Menentukan variabel penyelidikan

Menyusun pertanyaan berdasarkan fokus masalah

Mengusulkan cara mengeksplorasi secara ilmiah terhadap pertanyaan yang diberikan

Mengidentifikasi asumsi, bukti, dan penalaran dalam bacaan

Menyajikan data menggunakan beragam representasi yang sesuai

Menafsirkan data secara ilmiah

Menyimpulkan informasi berdasarkan analisis

Menjelaskan manfaat pengetahuan ilmiah bagi masyarakat

Mengevaluasi cara mengeksplorasi secara ilmiah terhadap pertanyaan yang diberikan

Mengevaluasi argumen dan bukti ilmiah dari beragam tipe sumber 


\section{Penutup}

Riset ini memberi hasil berupa desain pembelajaran untuk membimbing siswa sekolah dasar dalam memperoleh literasi saintifik yang keabsahan dan keandalan secara umum termasuk dalam kategori dapat digunakan. Melalui penerapan kepada 35 siswa di Kabupaten Kudus diperoleh bahwa desain ini dapat dilaksanakan oleh guru serta bisa diikuti oleh siswa. Simpulan yang kami sampaikan menunjukkan bahwa pembelajaran tematik dapat menjadi sarana untuk memandu siswa untuk memiliki literasi saintifik.

Dalam riset sosial, hasil yang diperoleh tidak memberi garansi bahwa keabsahan dan keandalan yang sama dapat berlaku untuk partisipan lain. Alasannya antara lain, ruang lingkup pembahasan berada dalam spektrum tertentu. Kalau hanya mengambil simpulan akhir tanpa memperhatikan rincian tertentu seperti metode dan fokus pembahasan, berarti yang terjadi adalah implantasi atau pencangkokan. Karena itu, kami menganggap bahwa kerja yang kami lakukan ini masih perlu dilanjutkan. Sehingga diharapkan penyusunan program ini tidak dianggap final, karena perlu dilakukan perbaikan berlanjut.

\section{Referensi}

Adisendjaja, Y. H. (2008). Analisis Buku Ajar Biologi SMA Kelas X di Kota Bandung Berdasarkan Literasi Sains. Bandung: Universitas Pendidikan Indonesia.

al-Syahrostān̄i, A. a.-F.-K. (2010). al-Milal wa al-Niḥal. Amman: Muassasat al-Halabi.

Boitani, P. (2015). Ulysses and the Stars. Strumenti Critici, 30(1), 3-18.

Crawford, G., \& Sen, B. (1996). Derivatives for Decision Makers: Strategic Management Issues. Hoboken: John Wiley \& Sons.

Creswell, J. W. (2014). Research Design Qualitative, Quantitative, and Mixed Methods Approaches (Edisi Keempat ed.). (V. Knight, Penyunt.) Thousand Oaks: SAGE Publications.

Cronbach, L. J. (1951, Februari 28). Coefficient Alpha and the Internal Structure of Tests. Psychometrika, 16, 297-334.

Dinata, A. N., Adisendjaja, Y. H., \& Amprasto. (2018, Maret 23). Pengaruh Field Trip terhadap Kemampuan Literasi Sains dan Sikap terhadap Sains Siswa SMA pada Materi Ekosistem. Assimilation: Indonesian Journal of Biology Education, 1(1), 8-13.

Fives, H., Huebner, W., Birnbaum, A. S., \& Nicolich, M. (2014, Juni 18). Developing a Measure of Scientific Literacy for Middle School Students. Science Education, 98(4), 549-580.

Fraenkel, J. R., Wallen, N. E., \& Hyun, H. H. (2012). How to Design and Evaluate Research in Education (Edisi Kedelapan ed.). (S. Kiefer, Penyunt.) New York City: McGraw-Hill Companies.

Gormally, C., Brickman, P., \& Lutz, M. (2012, Desember 1). Developing a Test of Scientific Literacy Skills (TOSLS): Measuring Undergraduates' Evaluation of Scientific Information and Arguments. CBE-Life Sciences Education, 11(4), 364-377.

Hawking, S. W., \& Mlodinow, L. (2010). The Grand Design. New York City: Bantam Books.

Hurd, P. d. (1998). Scientific Literacy: New Minds for a Changing World. Science Education, 82(3), 407-416.

Juliani, R. (2015). Rekonstruksi Rancangan Rencana Pelaksanaan Pembelajaran (RPP) Melalui Analisis Kesulitan Literasi Sains Peserta Didik Sekolah Menengah Pertama Pada Topik Listrik Dinamis. Bandung: Universitas Pendidikan Indonesia.

Kemdikbud. (2016). Peraturan Menteri Pendidikan dan Kebudayaan Republik Indonesia Nomor 24 Tahun 2016 tentang Kompetensi Inti dan Kompetensi Dasar Pelajaran Pada Kurikulum 2013 pada Pendidikan Dasar dan Pendidikan Menengah. Jakarta Pusat: Kementerian Pendidikan dan Kebudayaan Republik Indonesia .

Naturasari, H., Roshayanti, F., \& Nurwahyunani, A. (2016, Oktober 4). Profil Kualitas Literasi Sains Siswa SMP Se-Kabupaten Pati. Bioma: Jurnal Ilmiah Biologi, 5(2), 1895.

OECD. (2019). PISA 2018 Assessment and Analytical Framework. Paris: OECD Publishing.

OECD. (2019). Science Performance (PISA) (indicator). Paris: OECD Publishing.

OECD\&ADB. (2015). Education in Indonesia: Rising to the Challenge. Paris: OECD Publishing. 
Panchenko, D. (1994). Thales's Prediction of a Solar Eclipse. Journal for the History of Astronomy, 25(4), 275288.

Resor, C. W. (2017). Investigating Family, Food, and Housing Themes in Social Studies. Maryland: Rowman \& Littlefield Publishers.

Seefeldt, C. (2005). How to Work with Standards in the Early Childhood Classroom. New York City: Teachers College Press.

Setiawan, A. R. (2016, Januari 22). Ionia. АLОВАТИІО.

Setiawan, A. R. (2017). Penerapan Pendekatan Saintifik untuk Melatihkan Literasi Saintifik dalam Domain Kompetensi pada Topik Gerak Lurus di Sekolah Menengah Pertama. Bandung: Universitas Pendidikan Indonesia.

Setiawan, A. R. (2019, Oktober 2). Efektivitas Pembelajaran Biologi Berorientasi Literasi Saintifik. Thabiea : Journal of Natural Science Teaching, 2(2), 83-94.

Setiawan, A. R. (2019, September 30). Instrumen Penilaian untuk Pembelajaran Ekologi Berorientasi Literasi Saintifik. Assimilation: Indonesian Journal of Biology Education, 2(2), 42-46.

Setiawan, A. R. (2019, Desember 20). Literasi Saintifik Berdasarkan Kecerdasan Majemuk dan Motivasi Belajar. Media Penelitian Pendidikan: Jurnal Penelitian dalam Bidang Pendidikan dan Pengajaran, 13(2), 126-137.

Setiawan, A. R. (2019). Penerapan Pendekatan Saintifik untuk Melatih Literasi Saintifik dalam Domain Kompetensi pada Topik Gerak Lurus di Sekolah Menengah Pertama. Prosiding Seminar Nasional Fisika (SiNaFi) 2018 (hal. 7-13). Bandung: Universitas Pendidikan Indonesia.

Setiawan, A. R. (2019, Juni 26). Peningkatan Literasi Saintifik melalui Pembelajaran Biologi Menggunakan Pendekatan Saintifik. Journal of Biology Education, 2(1), 223-235.

Setiawan, A. R. (2019). Penyusunan Program Pembelajaran Biologi Berorientasi Literasi Saintifik. Dalam A. Nurwahyunani, A. G. Wicaksono, R. Rakhmawati, \& F. Kaswinarni (Penyunt.), Seminar Nasional Sains \& Entrepreneurship VI (SNSE VI). 1, hal. 348-355. Semarang: Universitas PGRI Semarang.

Setiawan, A. R. (2020, Januari 24). Pembelajaran Tematik Berorientasi Literasi Saintifik. . Jurnal Basicedu: Journal of Elementary Education, 04(01): ., 4(1), 71-80.

Setiawan, A. R. (2020, Maret 1). Pendidikan Literasi Finansial Melalui Pembelajaran Fiqh Mu'āmalāt Berbasis Kitab Kuning. (1, Penyunt.) Nazhruna: Jurnal Pendidikan Islam, 3(1), 138-159.

Setiawan, A. R., \& Mufassaroh, A. Z. (2019, Juni 28). Menyusun Soal Literasi Saintifik untuk Pembelajaran Biologi Topik Plantae dan Animalia. BIOSFER: Jurnal Biologi dan Pendidikan Biologi, 33-40.

Setiawan, A. R., \& Sari, D. R. (2019). A Simple Essay of Natural Science Curricula in Indonesia. Alobituis Research Society (ARS) (PrePrint).

Setiawan, A. R., Puspaningrum, M., \& Umam, K. (2019, Desember 6). Pembelajaran Fiqh Mu'āmalāt Berorientasi Literasi Finansial. Tarbawy: Indonesian Journal of Islamic Education, 6(2), 187-102.

Setiawan, A. R., Utari, S., \& Nugraha, M. G. (2017, September 22). Mengonstruksi Rancangan Soal Domain Kompetensi Literasi Saintifik Siswa SMP Kelas VIII pada Topik Gerak Lurus. Wahana Pendidikan Fisika, 2(2), 44-48.

Siayah, S., \& Setiawan, A. R. (2019, Juni 26). Multiple Intelligences Survey: Analysis on Validity and Reliability of Bahasa Indonesia Version Through Different Education Level. Alobituis Research Society (ARS) (PrePrint).

Siayah, S., Kurniawati, N. K., Velasufah, W., \& Setiawan, A. R. (2019, September 30). A Brief Explanation of

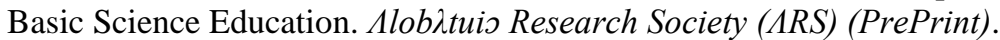

Sugiyono. (2018). Metode Penelitian Bisnis: Pendekatan Kuantitatif, Kualitatif, Kombinasi, dan R\&D (Edisi ke3 ed.). (S. Y. Suryandari, Penyunt.) Bandung: Alfabeta.

Utari, S., Karim, S., Prima, E. C., Saepuzaman, D., \& Nugaha, M. G. (2017). Recostructing the Physics Teaching Didactic based on Marzano's Learning Dimension on Training the Scientific Literacies. International Seminar on Mathematics, Science, and Computer Science Education (MSCEIS 2016). 812, hal. 012102. Bandung: Journal of Physics: Conference Series.

Velasufah, W., \& Setiawan, A. R. (2019, Agustus 9). Science Motivation Questionnaire II (SMQ-II): Analysis on Validity and Reliability of Bahasa Indonesia Version Through Various Learning Context. Alobituij Research Society (ARS) (PrePrint). 